\title{
Superior incident photon-to-current conversion efficiency of Mo-doped activated carbon supported CdS-sensitized solar cells
}

Ebru Batur

Siirt University: Siirt Universitesi

Sinan Kutluay

Siirt University: Siirt Universitesi

Orhan Baytar

Siirt University: Siirt Universitesi

Ömer Şahin

Siirt University: Siirt Universitesi

Sabit HOROZ ( $\nabla$ sabithoroz@siirt.edu.tr)

Siirt University: Siirt Universitesi

\section{Research Article}

Keywords: Activated carbon (AC), cadmium sulfide (CdS), incident photon-to-current efficiency (IPCE), semiconductor material-based solar cells

Posted Date: February 21st, 2022

DOI: https://doi.org/10.21203/rs.3.rs-1223510/v1

License: (c) (i) This work is licensed under a Creative Commons Attribution 4.0 International License. Read Full License 


\section{Abstract}

In this study, the performance of activated carbon (AC) produced from defatted black cumin (Nigella Sativa L.) by chemical activation with zinc chloride $\left(\mathrm{ZnCl}_{2}\right)$ activator in photovoltaic application is evaluated. It is of great importance to increase the photovoltaic efficiency of cadmium sulfide (CdS) based solar cells, which are widely used in photovoltaic applications, with AC support. The main purpose of the study is to determine how the incident photon-to-current conversion efficiency (IPCE) of undoped and Mo-doped AC supported CdS semiconductor materials changes in the presence of AC support material and to interpret the observed effect in the light of literature. For these reasons, in the study, AC supported CdS (CdS/AC) (5\%, 10\% and $15 \%$ by weight) and Mo-doped CdS/AC semiconductor materials with different molybdenum $(\mathrm{Mo})$ concentrations $(0.33 \%, 1 \%, 3 \%)$ are produced by chemical precipitation method. Produced CdS/AC and Mo-doped CdS/AC semiconductor materials are characterized by incident photon-to-current efficiency (IPCE), scanning electron microscopy (SEM), x-ray diffraction (XRD), energydispersive $x$-ray spectroscopy (EDX), and x-ray photoelectron spectroscopy (XPS) measurements. Based on the result values, the optimum CdS concentration with the highest IPCE (\%) value is determined as $10 \%$ (for CdS/AC). As a result of the experimental measurements, the optimum Mo concentration with the maximum IPCE (\%) value is found as $1 \%$ (for Mo-doped CdS/AC). In particular, it is clear that an appreciable increase (from $4.70 \%$ to $39.00 \%$ ) in IPCE (\%) of 1\% Mo-doped $10 \%$ CdS/AC semiconductor material is achieved when compared to pure CdS.

Thus, the ability to increase the photovoltaic efficiency of CdS-based solar cells, which are widely used in photovoltaic applications, with AC support has been clearly demonstrated. This study presents a new strategy to increase the solar cell efficiency of semiconductor-based solar cell structures using biowastebased AC supported CdS semiconductor materials.

\section{Highlights}

- Highly efficient novel nanocomposites, CdS/AC and Mo-doped CdS/AC, were successfully produced.

- XRD, EDX and XPS measurements confirmed the production of CdS/AC and Mo-doped CdS/AC materials.

- Mo-doped CdS/AC displayed remarkably higher incident photon-to-current efficiency than pure CdS.

- Great incident photon-to-current conversion efficiency of $39.00 \%$ was obtained with $1 \%$ Mo-doped $10 \%$ CdS/AC.

\section{Introduction}

The conversion of solar energy into usable electricity via a solid-state pn-junction-based photovoltaic (PV) device holds great opportunities in our quest to reduce our current dependence on fossil fuels and subsequently reduce harmful greenhouse gas emissions (Najm et al. 2021; Zhuk et al. 2017). Currently, global PV installations consist of monocrystalline silicon (c-Si), polycrystalline silicon (mc-Si), and thin- 
film technologies (Gulkowski, Zdyb, and Dragan 2019). The real trend in solar cell technology has to do with multicomponent thin film materials, which are believed to replace expensive crystalline silicon cell technology. Research has focused on identifying and improving the optimum light absorber, buffer and window layers (Islam and Thakur 2020; Vigil-Galán et al. 2015).

Cadmium sulfide (CdS) is an important II-VI compound semiconductor with high transparency, direct band gap transition (Eg 2.4 eV), high electron affinity (4.2 eV) and n-type conductivity (Horoz and Sahin 2017; Rajendra and Kekuda 2012). CdS also improves lattice heterojunction interface coupling, extends excess carrier lifetime, and optimizes band alignment of devices in which it is used. CdS thin films are considered as one of the most important materials for solar cell applications. It has a wide band gap with high optical transmittance and high electrical conductivity. For these reasons, it can be used as a window layer alongside other semiconductors such as CdS (Liu, Qiao, et al. 2020), CdTe (Bosio, Pasini, and Romeo 2020), CIGS (Ahmadpanah, Orouji, and Gharibshahian 2021) and ZnO (Liu, Luan, et al. 2020).

As a derivative of dye-sensitized solar cells, semiconductor-based solar cells attract extensive research due to their low cost effectiveness and ease of manufacture. Compared with conventional organic dyes, semiconductor materials offer some attractive advantages as light absorbers, including high molar extinction coefficient, tunable bandgap, large intrinsic dipole moment, and hot electron injection. In particular, the multi-exciton generation effect of semiconductor materials pushes the theoretical maximum power conversion efficiency of semiconductor-based solar cells up to $44 \%$, which exceeds the Shockley and Queisser limit for conventional semiconductor solar cells (Goodwin et al. 2018). So far, various semiconductor materials such as CdS (Lee et al. 2017), CdSe (Horoz et al. 2012), PbS (Huang and Zou 2015), and CdTe (Li et al. 2020) have been used as sensitizers to build semiconductor-based solar cells. However, due to the limited light absorption capacity or incomplete charge separation, all power conversion efficiencies are much lower than the maximum theoretical value.

Activated carbon (AC) is a promising carbonaceous material with superior properties such as high porosity and internal surface area (Ece et al. 2020; Kutluay, Ece, and Şahin 2020; Şahin et al. 2021). Chemical and physical activation methods of $\mathrm{AC}$ allow materials to produce a controlled pore distribution and surface area that defines the electrode/electrolyte interface for photovoltaic applications (solar cells) (Arbab et al. 2016; Vispute et al. 2011). AC is incorporated into the electrodes of photovoltaic devices as follows: electroconductive additives, supports for active materials, electron transfer catalysts, intercalation hosts, and substrates for current leads. For these reasons, AC is of course also very suitable as electrode materials for solar cells (Mehmood et al. 2016).

In a CdS-based solar cell, CdS semiconductor materials play a very important role as sensitizers. It is of great importance to increase the photovoltaic efficiency of CdS-based solar cells, which are widely used in photovoltaic applications, with AC support (Shao et al. 2019). Also, AC is included in the electrodes of photovoltaic devices as electro-conductive additives, support for active materials. For these reasons, AC is used to improve efficiency in solar cells. In a related study, it was observed that the efficiency of the solar cell cell designed in the absence of AC was $3.38 \%$, while the efficiency of the same solar cell cell 
with AC support was $5.45 \%$. This result shows that the use of AC as a support material in photovoltaic applications has a great impact (Mehmood et al. 2016).

To the authors' knowledge, there is no known production of Mo-doped AC (defatted black cumin (Nigella Sativa L.) waste biomass-based) supported CdS semiconductor materials, and this presents an innovation aspect of our proposed study. Here, instead of undoped-doped CdS, which is frequently used in the literature, AC-doped CdS (CdS/AC) (5\%, $10 \%$ and $15 \%$ by weight) and molybdenum (Mo)-doped with different concentrations $(0.33 \%, 1 \%$ and $3 \%$ by weight $) \mathrm{CdS} / \mathrm{AC}$ semiconductor materials are produced. The main purpose of the study is to determine how the incident photon-to-current conversion efficiency (IPCE) of undoped and Mo-doped AC supported CdS semiconductor-based solar cell structures change and to interpret the observed effect in the light of the literature.

\section{Material And Methods}

\subsection{Raw material and chemicals}

Defatted black cumin (Nigella Sativa L.) waste (DBCW), which is used as a precursor (raw material) in activated carbon (AC) production, was obtained from a local black cumin oil mill in Siirt province. DBCW samples were first dried in an oven at $80^{\circ} \mathrm{C}$ for 48 hours. The dried DBCW samples were sieved to a particle size range of 500-850 $\mu \mathrm{m}$ after grinding. Later, these DBCW samples were used as lead material in $\mathrm{AC}$ production. Zinc chloride $\left(\mathrm{ZnCl}_{2}\right)$ used in $\mathrm{AC}$ production was obtained from Shanghai Sinopharm chemical reagent company. Sodium hydroxide $(\mathrm{NaOH})$, ethanol $\left(\mathrm{C}_{2} \mathrm{H}_{5} \mathrm{OH}\right)$, hydrogen chloride $(\mathrm{HCl})$, sodium thiosulfate pentahydrate $\left(\mathrm{Na}_{2} \mathrm{~S}_{2} \mathrm{O}_{3} \cdot 5 \mathrm{H}_{2} \mathrm{O}\right)$ and potassium iodide $(\mathrm{KI})$ chemicals were purchased from the Scharlau company. Cadmium acetate dihydrate $\left(\mathrm{Cd}\left(\mathrm{CH}_{3} \mathrm{COO}\right)_{2} \cdot 2 \mathrm{H}_{2} \mathrm{O}\right)$ as a source of cadmium $(\mathrm{Cd})$, sodium sulfide $\left(\mathrm{Na}_{2} \mathrm{~S}\right)$ as a source of sulfur $(\mathrm{S})$, and ammonium molybdenum tetrahydrate $\left(\left(\mathrm{NH}_{4}\right)_{6} \mathrm{Mo}_{7} \mathrm{O}_{24} \cdot 4 \mathrm{H}_{2} \mathrm{O}\right)$ as a source of molybdenum (Mo) were obtained from Sigma-Aldrich. Solvents in the study were prepared using deionized water. All chemicals/reagents used in this study were used without purification in the experiments as they were of standard analytical purity.

\subsection{Production of AC}

In $\mathrm{AC}$ production, approximately $3 \mathrm{~g}$ of dried $\mathrm{DBCW}$ was mixed with $\mathrm{ZnCl}_{2}$ activator at room temperature at an impregnation rate of $105 \%$ ( $\mathrm{DBCW} / \mathrm{ZnCl} 2$, mass ratio), and this mixture was allowed to soak for 1 minute (impregnation time). Then, the impregnated sample was placed in a heat resistant container and subjected to carbonization and activation process under $\mathrm{N}_{2}$ flow for 60 minutes in a horizontal tube typehigh temperature reactor at a heating rate of $10^{\circ} \mathrm{C} / \mathrm{min}$ from room temperature to the desired final temperature $\left(550^{\circ} \mathrm{C}\right)$. The product obtained as a result of this process was cooled to room temperature under $\mathrm{N}_{2}$ atmosphere in the reactor. This product was then washed first with $0.5 \mathrm{M} \mathrm{HCl}$, then repeatedly washed with $\mathrm{C}_{2} \mathrm{H}_{5} \mathrm{OH}$ and deionized hot water until the $\mathrm{pH}$ of the rinse water was neutral, and finally dried at $80^{\circ} \mathrm{C}$ for 24 hours. The resulting $\mathrm{AC}$ was then stored in an airtight container to be used as support material. 


\subsection{Production of CdS}

In the CdS production process, $0.05 \mathrm{M} \mathrm{Cd}\left(\mathrm{CH}_{3} \mathrm{COO}\right)_{2} \cdot 2 \mathrm{H}_{2} \mathrm{O}$ and $0.05 \mathrm{M} \mathrm{Na}_{2} \mathrm{~S}$ were dissolved in two clean beakers containing $50 \mathrm{~mL}$ of distilled water using chemical precipitation technique. Then, these two solutions were transferred to a different beaker and mixed with a magnetic stirrer for about 1 hour. At the end of this period, the mixing process was stopped and the solution obtained was allowed to settle to the bottom, and then the precipitated sample was separated from the solvent with the filter paper. After this process, the obtained sample was washed several times with distilled water and $\mathrm{C}_{2} \mathrm{H}_{5} \mathrm{OH}$ to remove unwanted components. After washing, the wet precipitate was dried in an oven at $80^{\circ} \mathrm{C}$ for 10 hours. CdS sample obtained after drying was ground in a mortar to produce CdS semiconductor material.

\subsection{Production of AC supported CdS}

Different ratios such as $5 \%, 10 \%$ and $15 \% \mathrm{CdS} / \mathrm{AC}$ were used in the production of AC supported CdS (CdS/AC). For this purpose, in the $\mathrm{CdS} / \mathrm{AC}$ production process, $0.05 \mathrm{M} \mathrm{Cd}\left(\mathrm{CH}_{3} \mathrm{COO}\right)_{2} \cdot 2 \mathrm{H}_{2} \mathrm{O}$ and $0.05 \mathrm{M}$ $\mathrm{Na}_{2} \mathrm{~S}$ were dissolved in two clean beakers containing $50 \mathrm{~mL}$ of distilled water using chemical precipitation technique. Then, these two solutions were transferred to a different beaker containing the calculated amount $(3.24 \mathrm{~g})$ of AC for different ratios $(5 \%, 10 \%$ and $15 \% \mathrm{CdS} / \mathrm{AC})$ and mixed with a magnetic stirrer for about 1 hour. At the end of this period, the mixing process was stopped and the solution obtained was allowed to settle to the bottom, and then the precipitated sample was separated from the solvent with the filter paper. After this process, the obtained sample was washed several times with distilled water and $\mathrm{C}_{2} \mathrm{H}_{5} \mathrm{OH}$ to remove unwanted components. After washing, the wet precipitate was dried in an oven at $80^{\circ} \mathrm{C}$ for 10 hours. CdS/AC sample obtained after drying was ground in a mortar to produce CdS/AC semiconductor material. This process was also carried out separately for the synthesis of $5 \%, 10 \%$ and $15 \% \mathrm{CdS} / \mathrm{AC}$ semiconductor materials.

\subsection{Production of Mo-doped AC supported CdS}

I. For $0.33 \%$ Mo-doped CdS/AC, $0.00016 \mathrm{M}\left(\mathrm{NH}_{4}\right)_{6} \mathrm{Mo}_{7} \mathrm{O}_{24} \cdot 4 \mathrm{H}_{2} \mathrm{O}$ was added onto $0.05 \mathrm{M}$ $\mathrm{Cd}\left(\mathrm{CH}_{3} \mathrm{COO}\right)_{2} \cdot 2 \mathrm{H}_{2} \mathrm{O}$ aqueous solution and the procedures mentioned in 2.4 were repeated.

II. For $1 \%$ Mo-doped CdS/AC, $0.0005 \mathrm{M}\left(\mathrm{NH}_{4}\right)_{6} \mathrm{Mo}_{7} \mathrm{O}_{24} \cdot 4 \mathrm{H}_{2} \mathrm{O}$ was added onto $0.05 \mathrm{M} \mathrm{Cd}\left(\mathrm{CH}_{3} \mathrm{COO}\right)_{2} \cdot 2 \mathrm{H}_{2} \mathrm{O}$ aqueous solution and the procedures mentioned in 2.4 were repeated.

III. For $3 \%$ Mo-doped CdS/AC, $0.0015 \mathrm{M}\left(\mathrm{NH}_{4}\right)_{6} \mathrm{Mo}_{7} \mathrm{O}_{24} \cdot 4 \mathrm{H}_{2} \mathrm{O}$ was added onto $0.05 \mathrm{M} \mathrm{Cd}\left(\mathrm{CH}_{3} \mathrm{COO}\right)_{2} \cdot 2 \mathrm{H}_{2} \mathrm{O}$ aqueous solution and the procedures mentioned in 2.4 were repeated.

\subsection{Design of undoped and Mo-doped AC supported CdS semiconductor material-based solar cells}

How the $\mathrm{Zn}_{2} \mathrm{SnO}_{4}$ (ZTO) oxide semiconductor, which is used as a photo-anode in a semiconductor-based solar cell, is obtained and how it is coated on F-doped $\mathrm{SnO}_{2}$ conductive glasses is explained in detail below; 
Nano-sized ZTO was obtained in powder form by the solvothermal method. In the solvothermal method; Zinc acetate $\left(\mathrm{ZnC}_{4} \mathrm{H}_{6} \mathrm{O}_{4}\right)$ and tin chloride $\left(\mathrm{SnCl}_{2}\right)$ were placed in a certain amount of $\mathrm{C}_{2} \mathrm{H}_{5} \mathrm{OH}$ in accordance with the stoichiometer and mixed with a magnetic stirrer. A certain amount of $\mathrm{NaOH}$ aqueous solution was added to the resulting mixture and mixed until a homogeneous mixture was obtained (average $30 \mathrm{~min}$ ). The homogeneous mixture was transferred into the autoclave and ZTO was obtained in powder form by heating in an oven at a certain temperature. ZTO paste was obtained by mixing ZTO in powder form with a small amount of $\mathrm{C}_{2} \mathrm{H}_{5} \mathrm{OH}$. A certain amount of ZTO paste was coated on F-doped $\mathrm{SnO}_{2}$ conductive glasses with the doctor blade technique so that it spreads evenly. The obtained samples were annealed at high temperature in the furnace to obtain the desired substrates. After the desired ZTO anodes were obtained, these ZTO anodes were immersed in the produced undoped and Mo-doped $\mathrm{CdS} / \mathrm{AC}$ semiconductor materials and left for 24 hours. Thus, a good coating of the semiconductors on the ZTO was achieved.

$\mathrm{Cu}_{2} \mathrm{~S}$ counter electrode, another important part of the solar cell, was obtained by following the steps given below;

$\mathrm{Cu}_{2} \mathrm{~S}$ counter (counter) electrodes were obtained on F-doped $\mathrm{SnO}_{2}$ conductive glasses by doctor blade method. In short; $0.5 \mathrm{M}$ copper (II) nitrate $\left(\mathrm{Cu}\left(\mathrm{NO}_{3}\right)_{2}\right)$ chemical was dissolved in 100 microliter $(\mu \mathrm{L})$ methanol $\left(\mathrm{CH}_{3} \mathrm{OH}\right)$ and some of the solution obtained was dropped on the F-doped $\mathrm{SnO}_{2}$ conductive glass. After the dripping process, the $\mathrm{Cu}\left(\mathrm{NO}_{3}\right)_{2}$ solution was homogeneously distributed on the conductive glass by the doctor knife method. Then, $1 \mathrm{M}$ sodium sulfide $\left(\mathrm{Na}_{2} \mathrm{SO}_{3}\right)$ was mixed in distilled water and $\mathrm{CH}_{3} \mathrm{OH}$ solvent 1:1 by volume, and a few drops of the obtained solution were dropped onto the conductive glass containing $\mathrm{Cu}\left(\mathrm{NO}_{3}\right)_{2}$. Thus, the color of the conductive glass changed from blue to brown. The conductive glass was washed with pure sy and dried in nitrogen environment. This was applied a second time by repeating the above-mentioned processes in the same way, and the resulting film was calcined at $450^{\circ} \mathrm{C}$ for $30 \mathrm{~min}$ in an ash oven and then left to cool. Thus, the $\mathrm{Cu}_{2} \mathrm{~S}$ counter (counter) electrode was obtained. These counter electrodes were obtained for each sample produced. Thus, semiconductor-based solar cell cells were designed by connecting the photo-anodes (ZTO) and $\mathrm{Cu}_{2} \mathrm{~S}$ counter (counter) electrodes with a coupler clamps. While taking incident photon-to-current efficiency (IPCE) measurements, $10 \mu \mathrm{L}$ of polysulfide electrolyte solution, the synthesis method of which is given below, was dropped between the photoanode/electrode obtained in order to ensure electron transfer between the photo-anode and the electrode. Synthesis of a polysulfide electrolyte: It was obtained by mixing the chemicals $5 \mathrm{M} \mathrm{Na}_{2} \mathrm{SO}_{3}, 2 \mathrm{M}$ sulfur (S), and $0.2 \mathrm{M}$ potassium chloride (KCl) in a solvent consisting of distilled water and $\mathrm{CH}_{3} \mathrm{OH}$ in a 1:1 volumetric ratio.

In order to calculate both the power conversion efficiency of the produced undoped and Mo-doped $\mathrm{CdS} / \mathrm{AC}$ semiconductor materials and to examine their photovoltaic properties, IPCE measurements were made for the semiconductor-based solar cell cells designed as a result of the above-mentioned processes, and the data were interpreted using the curves obtained. 


\subsection{Characterizations}

Semiconductor materials produced within the scope of the study were characterized by IPCE, scanning electron microscopy (SEM), x-ray diffraction (XRD), energy-dispersive $x$-ray spectroscopy (EDX) and x-ray photoelectron spectroscopy (XPS) measurements. At this stage, first of all, photovoltaic properties of pure CdS, CdS/AC and Mo-doped CdS/AC semiconductor materials were determined by IPCE measurements. Then, the morphological and structural properties of CdS/AC and Mo-doped CdS/AC semiconductor materials, which provide the best efficiency, were investigated by making SEM and XRD measurements, respectively. The basic element components of the produced semiconductor materials were determined by EDX (Bruker, Quantax ED-XS, Germany) analysis. XPS spectra of these materials were obtained using a monochrome Al-Ka X-ray source $(1486.71 \mathrm{eV})$ and a SPECS-Flex mod XPS device.

\section{Results And Discussion}

\subsection{Evaluation of the performance of AC in CdS semiconductor material-based solar cells}

Within the scope of the study, the solar cell efficiency of CdS, CdS/AC and Mo-doped CdS/AC semiconductor based solar cell structures was investigated. For this purpose, CdS (CdS/AC) and Modoped CdS/AC materials produced by chemical precipitation method on AC were reduced. CdS, CdS/AC and Mo-doped CdS/AC semiconductor materials obtained as a result of these processes were characterized by IPCE, SEM, XRD, EDX and XPS measurements.

\subsection{IPCE measurements}

Here, first of all, IPCE measurements were carried out to examine the solar cell efficiency of semiconductor-based solar cell structures obtained by using CdS/AC semiconductors with different CdS concentrations such as $5 \%, 10 \%$ and $15 \%$ and to determine the optimum CdS concentration that gives the best efficiency. The IPCE spectra of CdS/AC semiconductor-based solar cell structures with different CdS concentrations obtained as a result of the measurements are shown in Figure 1. According to Figure 1, IPCE (\%) values of CdS/AC semiconductor-based solar cell structures with different CdS concentrations at $450 \mathrm{~nm}$ are listed in Table 1. Based on the values given in Table 1, the optimum CdS concentration with the best IPCE (\%) value or the best solar cell efficiency was determined as $10 \%$. Based on the values given in Table 1, two observations are important. First, there is a notable increase in the IPCE (\%) efficiency of the CdS semiconductor-based solar cell structure in the presence of AC. The main reason for this is that AC increases electron mobility in the solar cell structure due to its good electronic properties. Another important observation is the decrease in IPCE (\%) at high CdS concentrations. Defects at high concentrations reduce solar cell efficiency by allowing light to generate heat instead of electricity, providing new recombination pathways (loss). Furthermore, the defects cause deep energy levels in the semiconductor band gap, which reduces the carrier lifetime and quantum efficiency of solar cells (Ece et al. 2021; Kutluay et al. 2021; Lin et al. 2017; Yan et al. 2019). 
Table 1

The IPCE (\%) values of CdS/AC semiconductor-based solar cell structures with different CdS concentrations at $450 \mathrm{~nm}$

\begin{tabular}{|ll|}
\hline Materials & IPCE (\%) values \\
\hline CdS & 4.70 \\
\hline $5 \% \mathrm{CdS} / \mathrm{AC}$ & 14.67 \\
\hline $10 \% \mathrm{CdS} / \mathrm{AC}$ & 22.10 \\
\hline $15 \% \mathrm{CdS} / \mathrm{AC}$ & 17.09 \\
\hline
\end{tabular}

After determining the best CdS concentration value, $10 \% \mathrm{Cd} / \mathrm{AC}$ semiconductor material was doped with Mo element and the effect of doping on the solar cell structure was investigated. In Figure 2, IPCE (\%) spectra of Mo-doped 10\% CdS/AC semiconductor-based solar cell structures with different Mo concentrations $(0.33 \%, 1 \%$ and $3 \%)$ are shown. According to Figure 2 , IPCE (\%) values of Mo-doped $10 \%$ $\mathrm{CdS} / \mathrm{AC}$ semiconductor-based solar cell structures with different Mo concentrations at $450 \mathrm{~nm}$ are listed in Table 2. As can be clearly seen in Table 2, Mo-doped 10\% CdS/AC semiconductor-based solar cell structure plays an important role in increasing the IPCE (\%) value. One of the most important advantages of the Mo dopant metal is that it forms a highly porous structure in the semiconductor material. Thanks to the porosity of the semiconductor material, it absorbs more light, thus causing a remarkable increase in the efficiency of the solar cell structure (Mehmood et al. 2017). However, the defects formed despite the porous structure in the presence of high Mo dopant metal caused a decrease in IPCE (\%). Thus, as a result of the experimental measurement, the Mo concentration with the best IPCE (\%) value was determined as $1 \%$. In particular, it is clear that an appreciable increase in IPCE (\%) of $10 \%$ CdS/AC semiconductor material with $1 \%$ Mo-doped is achieved when compared with pure CdS and $10 \% \mathrm{CdS} / \mathrm{AC}$ materials.

Table 2

The IPCE (\%) values of Mo-doped CdS/AC semiconductor-based solar cell structures with different Mo concentrations at $450 \mathrm{~nm}$

\begin{tabular}{|ll|}
\hline Materials & IPCE (\%) values \\
\hline $10 \%$ CdS/AC & 22.10 \\
\hline 0.33\% Mo-doped 10\% CdS/AC & 28.82 \\
\hline 1\% Mo-doped 10\% CdS/AC & 39.00 \\
\hline $3 \%$ Mo-doped 10\% CdS/AC & 30.95 \\
\hline
\end{tabular}

\subsection{SEM analysis}

SEM images of AC, $10 \% \mathrm{CdS} / \mathrm{AC}$ and Mo (1\%)-doped 10\% CdS/AC are presented in Figure 3. As seen in Figure 3, CdS and Mo-doped CdS materials are homogeneously dispersed on the AC surface. When SEM 
images of CdS/AC and Mo-doped CdS/AC materials are compared with SEM image of AC, it can be said that CdS and Mo-doped CdS/AC semiconductor materials cause microstructure of pores on the AC surface. In addition, it can be said that CdS/AC and Mo-doped CdS/AC semiconductor materials are nano-structured, supported by XRD results. In the related study (Huang et al. 2017), AC supported CdS particle size varies in the range of $10-30 \mathrm{~nm}$ and CdS weaves AC pores like a flower; In other words, it was stated that AC caused the formation of pores on its surface. Moreover, it can be said that CdS and Mo form a homogeneous microporous structure on the surface by settling in the mesopores.

\subsection{XRD analysis}

The XRD diffraction patterns of AC, CdS, 10\% CdS/AC and Mo(1\%)-doped 10\% CdS/AC materials are shown in Figure 4. As seen here, pure CdS semiconductor material has a cubic structure, while AC supported undoped and Mo-doped CdS semiconductor materials exhibit a hexagonal structure. The main reason for this situation is that $A C$, which has a porous structure, plays an active role in changing the structure of the CdS semiconductor material. Another remarkable observation is that the structure of the AC supported CdS semiconductor material does not change, although the AC supported CdS semiconductor material is doped with Mo metal. This result can be accepted as an indication that the production process has been carried out successfully, as it shows that no oxidation or an undesirable compound is formed in the production process. With the help of XRD diffraction patterns, the crystallite size of the Mo-doped CdS/AC semiconductor material produced using the Debye-Scherrer formula shown

in Equation (1) was calculated as $11.09 \mathrm{~nm}$. This numerical data can be considered as an indication that the semiconductor material is produced at nanoscale.

$$
\mathrm{D}=\frac{k \times \lambda}{\beta \times \cos \left(\theta_{B}\right)}
$$

1

Here, $\mathrm{D}$ is the crystallite size, $k$ is the Scherrer constant, $\lambda$ is the wavelength of the $\mathrm{x}$-ray, $\beta$ is the peak half-width (FWHM) in radians, and $\theta_{B}$ is the Bragg angle of the peak.

\subsection{EDX analysis}

Elemental properties of $10 \% \mathrm{CdS} / \mathrm{AC}$ and Mo (1\%)-doped 10\% CdS/AC materials were investigated by performing EDX measurements. The EDX spectra of CdS/AC and Mo-doped CdS/AC semiconductor materials are shown in Figure 5 and Figure 6, respectively. In these findings, the detection of the presence of $\mathrm{C}, \mathrm{Cd}, \mathrm{S}$ and Mo metals is an indication of the successful production of undoped and Mo-doped ACsupported CdS semiconductor materials.

\subsection{XPS analysis}

XPS measurements were performed to evaluate the bonding energies and surface chemical compositions of $\mathrm{AC}, \mathrm{CdS}, 10 \% \mathrm{CdS} / \mathrm{AC}$ and Mo (1\%)-doped $10 \% \mathrm{CdS} / \mathrm{AC}$ materials in more detail. For this purpose, the 
XPS spectra of the C 1s, Cd 3d, S $2 p$ and Mo $3 d$ regions obtained for the mentioned semiconductor materials are shown in Figure 7.

The peaks observed at 282.01, 281.92 and $282.13 \mathrm{eV}$ for AC, CdS/AC and Mo-doped CdS/AC semiconductor materials (Figure $7 \mathrm{a}$ ) show the XPS spectrum of the $1 \mathrm{~s}$ region of $\mathrm{C}$ (Chen, Wang, and Fang 2020; Kutluay 2021).

For CdS, CdS/AC and Mo-doped CdS/AC semiconductor materials, it was observed that two corresponding binding energies of $\mathrm{Cd} 3 \mathrm{~d}_{5 / 2}$ and $\mathrm{Cd} 3 \mathrm{~d}_{3 / 2}$ were found at $405.38,404.36,403.67 \mathrm{eV}$ and $412.08,411.14,410.55 \mathrm{eV}$, respectively (Figure 7b). The cleavage energy between the two $3 \mathrm{~d}$ orbitals of about $6.70 \mathrm{eV}$ observed for these semiconductor materials is indicative of the $\mathrm{Cd}^{2+}$ ion (Fan et al. 2012).

The XPS spectra in Figure 7c show the binding energies of the S $2 p$ sites in CdS, CdS/AC and Mo-doped CdS/AC semiconductor materials at 161.51, 160.89 and $160.16 \mathrm{eV}$, respectively. These results are in good agreement with the reference values for the $\mathrm{S}^{2-}$ ion (Fantauzzi et al. 2015).

The XPS spectrum of the Mo 3d region given in Figure 7d for the Mo-doped CdS/AC semiconductor material is attributed to the binding energies of ${\mathrm{Mo} 3 \mathrm{~d}_{3 / 2}}$ and $\mathrm{Mo} 3 \mathrm{~d}_{5 / 2}$ at 235.15 and $229.30 \mathrm{eV}$, respectively (Singer et al. 1996).

Based on the comparison of XPS analysis findings with the literature, it was concluded that CdS, CdS/AC and Mo-doped CdS/AC semiconductor materials were successfully produced.

\section{Conclusions}

In the current study, CdS/AC and Mo-doped CdS/AC semiconductor materials were produced by using AC as a support material instead of the undoped-doped CdS semiconductor materials, which are frequently used in the literature. The produced CdS/AC and Mo-doped CdS/AC semiconductor materials were characterized by IPCE, SEM, XRD, EDX and XPS measurements. When the SEM images of AC, CdS/AC and Mo-doped CdS/AC materials are compared, it can be said that CdS and Mo form a homogeneous microporous structure on the surface by settling in the mesopores. The crystallite size of the Mo-doped CdS/AC semiconductor material was calculated as $11.09 \mathrm{~nm}$. This numerical data can be considered as an indication that the semiconductor material is produced at nanoscale. Based on the comparison of EDX and XPS analysis findings with the literature, it was concluded that CdS, CdS/AC and Mo-doped $\mathrm{CdS} / \mathrm{AC}$ semiconductor materials were successfully produced. Also, based on the result values, the optimum CdS concentration with the highest IPCE (\%) value or the highest solar cell efficiency was determined as $10 \%$ (for $\mathrm{CdS} / \mathrm{AC}$ ). As a result of the experimental measurements, the Mo concentration with the maximum IPCE (\%) value was found as $1 \%$ (for Mo-doped CdS/AC). In particular, it is clear that a remarkable increase (from $4.70-39.00 \%$ ) in the IPCE (\%) value of $1 \%$ Mo-doped $10 \% \mathrm{CdS} / \mathrm{AC}$ semiconductor material is achieved when compared to pure CdS. Thus, the ability to increase the photovoltaic efficiency of CdS-based solar cells, which are widely used in photovoltaic applications, with AC support has been clearly demonstrated. In addition, this study presents a new strategy to increase the 
solar cell efficiency of semiconductor-based solar cell structures using biowaste-based AC supported CdS semiconductor materials.

\section{Declarations}

\section{Acknowledgments}

This work was supported by Siirt University Scientific Research Projects Coordination Unit under Project Number 2020-SiÜFEB-019.

Authors' contributions: Ömer Şahin: supervision and review. Ebru Batur: conceptualization, investigation, and visualization. Sinan Kutluay: conceptualization, investigation, visualization, writing - review and editing. Sabit Horoz: review and editing. Orhan Baytar: conceptualization, investigation, visualization, writing-review and editing.

Data availability: Not applicable

Compliance with ethical standards

Ethical approval: The authors declare that they have no conflict of interest.

Consent to participate: Not applicable

Consent to publish: Not applicable

Competing interests: The authors declare that they have no competing interests.

\section{References}

1. Ahmadpanah F, Sadat AA, Orouji, and Iman Gharibshahian (2021) 'Improving the efficiency of CIGS solar cells using an optimized p-type CZTSSe electron reflector layer'. J Mater Sci: Mater Electron 32:22535-22547

2. Arbab A, Ayoub KC, Sun IA, Sahito MB, Qadir YS, Choi, Sung Hoon Jeong (2016) 'A Novel ActivatedCharcoal-Doped Multiwalled Carbon Nanotube Hybrid for Quasi-Solid-State Dye-Sensitized Solar Cell Outperforming Pt Electrode'. ACS Appl Mater Interfaces 8:7471-7482

3. Bosio A, Pasini S, and Nicola Romeo (2020). 'The history of photovoltaics with emphasis on CdTe solar cellsmodules', Coatings, 10: 344

4. Chen X, Wang X, De Fang (2020) 'A review on C1s XPS-spectra for some kinds of carbon materials'. Fullerenes, Nanotubes and Carbon Nanostructures 28:1048-1058

5. Ece M, Şakir A, Ekinci S, Kutluay Ömer, Şahin, Sabit Horoz (2021) 'Facile synthesis and comprehensive characterization of Ni-decorated amine groups-immobilized Fe304@SiO2 magnetic nanoparticles having enhanced solar cell efficiency'. J Mater Sci: Mater Electron 32:18192-18204 
6. Ece M, Şakir S, Kutluay Ömer, Şahin, and Sabit Horoz (2020) 'Development of Novel Fe304/AC@Si02@1,4-DAAQ Magnetic Nanoparticles with Outstanding VOC Removal Capacity: Characterization, Optimization, Reusability, Kinetics, and Equilibrium Studies'. Ind Eng Chem Res 59:21106-21123

7. Fan C, Wang X, Sang H, Wang F (2012) 'Effects of Composition and Calcination Temperature on Photocatalytic H 2 Evolution over Cd 1 - x Zn x S / SiO 2 from Glycerol and Water Mixture', International Journal of Photoenergy, 2012

8. Fantauzzi M, Elsener B, Atzei D, Rigoldi A, Antonella Rossi (2015) 'Exploiting XPS for the identification of sulfides and polysulfides'. RSC Adv 5:75953-75963

9. Goodwin H, Jellicoe TC, Nathaniel JLK, Davis, Marcus LB (2018) 'Multiple exciton generation in quantum dot-based solar cells'. Nanophotonics 7:111-126

10. Gulkowski S, Zdyb A, Dragan P (2019) 'Experimental efficiency analysis of a photovoltaic system with different module technologies under temperate climate conditions'. Applied Sciences 9:141

11. Horoz S, Lu L, Dai Q, Chen J, Yakami B, Pikal JM, Wang W, Jinke Tang (2012) 'CdSe quantum dots synthesized by laser ablation in water and their photovoltaic applications'. Appl Phys Lett 101:223902

12. Horoz S, and Omer Sahin (2017) 'Synthesis, characterizations and photovoltaic properties of Crdoped CdS QDs'. J Mater Sci: Mater Electron 28:17784-17790

13. Huang H-B, Wang Yu, Cai F-Y, Zhang Wen-BinJNing, Liu C, Cao H-L, and Jian Lü (2017). 'Photodegradation of Rhodamine B over Biomass-Derived Activated Carbon Supported CdS Nanomaterials under Visible Irradiation',Frontiers in Chemistry, 5

14. Huang Z (2015) and Xiaoping Zou. 'Superior Photocurrent of Quantum Dot Sensitized Solar Cells Based on PbS: In/CdS Quantum Dots', International Journal of Photoenergy, 2015: 657871

15. Islam MT, Thakur AK (2020) 'Two stage modelling of solar photovoltaic cells based on Sb2S3 absorber with three distinct buffer combinations'. Sol Energy 202:304-315

16. Kutluay S (2021) 'Excellent adsorptive performance of novel magnetic nano-adsorbent functionalized with 8-hydroxyquinoline-5-sulfonic acid for the removal of volatile organic compounds (BTX) vapors', Fuel, 287: 119691

17. Kutluay S Mehmet Şakir Ece, and Ömer Şahin. 2020. 'Synthesis of magnetic Fe304/AC nanoparticles and its application for the removal of gas-phase toluene by adsorption process', International Journal of Chemistry and Technology, 4:146-55

18. Kutluay S, Horoz S, Şahin Ömer, Ekinci A, Mehmet Şakir E (2021) 'Highly improved solar cell efficiency of Mn-doped amine groups-functionalized magnetic Fe304@SiO2 nanomaterial'. Int J Energy Res 45:20176-20185

19. Lee Y-S, Gopi CVVM, Reddy AE, Nagaraju C, Hee-Je K (2017) 'High performance of TiO2/CdS quantum dot sensitized solar cells with a $\mathrm{Cu}-Z n S$ passivation layer'. New J Chem 41:1914-1917

20. Li H, Lu W, Song B, Zhou J, Zhao G, and Gaorong Han (2020) 'The design of Mn2+\&Co2+ co-doped CdTe quantum dot sensitized solar cells with much higher efficiency'. RSC Adv 10:35701-35708 
21. Lin Y, Chen B, Zhao F, Zheng X, Deng Y, Shao Y, Fang Y, Bai Y, Wang C, Jinsong Huang (2017) 'Matching Charge Extraction Contact for Wide-Bandgap Perovskite Solar Cells'. Adv Mater 29:1700607

22. Liu H, Luan H, Jie YS, Wang HF, Sui Y, Lv S, Lili Y (2020) 'The fabrication of ZnO solar cells doublesensitized by CdS@ CdSe quantum dots through anion exchange method'. J Mater Sci: Mater Electron 31:20080-20089

23. Liu X, Qiao Y, Liu Y, Liu J, Jia E, Chang S, Shen X, Li S, Ke Cheng (2020) 'Enhanced open circuit voltage of Sb2Se3/CdS solar cells by annealing Se-rich amorphous Sb2Se3 films prepared via sputtering process'. Sol Energy 195:697-702

24. Mehmood I, Liu Y, Chen K, Shah AH, Chen W (2017) 'Mn doped CdS passivated CulnSe2 quantum dot sensitized solar cells with remarkably enhanced photovoltaic efficiency'. RSC Adv 7:33106-33112

25. Mehmood U, Zaheer Aslam M, Shawabkeh RA, Hussein IA, Ahmad W, Ghaffar Rana A (2016) 'Improvement in Photovoltaic Performance of Dye Sensitized Solar Cell Using Activated Carbon-TiO Composites-Based Photoanode'. IEEE J Photovolt 6:1191-1195

26. Najm A, Soheil P, Chelvanathan SK, Tiong MT, Ferdaous SA, Shahahmadi Y, Yusoff K, Sopian, and Nowshad Amin (2021). 'Numerical Insights into the Influence of Electrical Properties of n-CdS Buffer Layer on the Performance of SLG/Mo/p-Absorber/n-CdS/n-ZnO/Ag Configured Thin Film Photovoltaic Devices', Coatings, 11: 52

27. Rajendra BV, and Dhananjaya Kekuda (2012) 'Flexible cadmium telluride/cadmium sulphide thin film solar cells on mica substrate'. J Mater Sci: Mater Electron 23:1805-1808

28. Shao M, Shao Y, Ding S, Tong R, Zhong X, Yao L, Ip W, Xu B, Shi X, Sun Y-Y, Wang X, and Hui Pan (2019). 'Carbonized MoS2: Super-Active Co-catalyst for High-Efficient Water Splitting on CdS',ACS Sustainable Chemistry \& Engineering, 7

29. Singer, Irwin T, Le-Mogne C, Donnet, Martin J (1996) 'In situ analysis of the tribochemical films formed by $\mathrm{SiC}$ sliding against $\mathrm{Mo}$ in partial pressures of $\mathrm{SO} 2, \mathrm{O} 2$, and $\mathrm{H} 2 \mathrm{~S}$ gases'. Journal of Vacuum Science \& Technology A: Vacuum, Surfaces, and Films 14:38-45

30. Şahin Ömer, Kutluay S, Horoz S, Mehmet Şakir E (2021) 'Fabrication and characterization of 3,4diaminobenzophenone-functionalized magnetic nanoadsorbent with enhanced VOC adsorption and desorption capacity'. Environ Sci Pollut Res 28:5231-5253

31. Vigil-Galán O, Maykel Courel JA, Andrade-Arvizu Y, Sánchez M, Espíndola-Rodríguez E, Saucedo D, Seuret-Jiménez, and Matthew Titsworth (2015) 'Route towards low cost-high efficiency second generation solar cells: current status and perspectives'. J Mater Sci: Mater Electron 26:5562-5573

32. Vispute RD, Vats A, Venkatesan V, Seiser A, Dozier J, Feldman J, and Lance Robinson (2011). 'Electrical Conducting Diamond Thin-Films: An Alternative Counter Electrode Material for Dye Sensitized Solar Cells', MRS Online Proceedings Library, 1282: 1404

33. Yan H, Tang Y, Sui X, Liu Y, Gao B, Liu X, Liu SF, Hou J, Ma W (2019) 'Increasing Quantum Efficiency of Polymer Solar Cells with Efficient Exciton Splitting and Long Carrier Lifetime by Molecular Doping at Heterojunctions'. ACS Energy Letters 4:1356-1363 
34. Zhuk S, Kushwaha A, Wong TKS, Masudy-Panah S, Smirnov A, Goutam Kumar D (2017) 'Critical review on sputter-deposited Cu2ZnSnS4 (CZTS) based thin film photovoltaic technology focusing on device architecture and absorber quality on the solar cells performance'. Sol Energy Mater Sol Cells 171:239-252

\section{Figures}

\section{Figure 1}

The IPCE spectra of CdS/AC semiconductor-based solar cell structures with different CdS concentrations

\section{Figure 2}

The IPCE spectra of Mo-doped CdS/AC semiconductor-based solar cell structures with different Mo concentrations
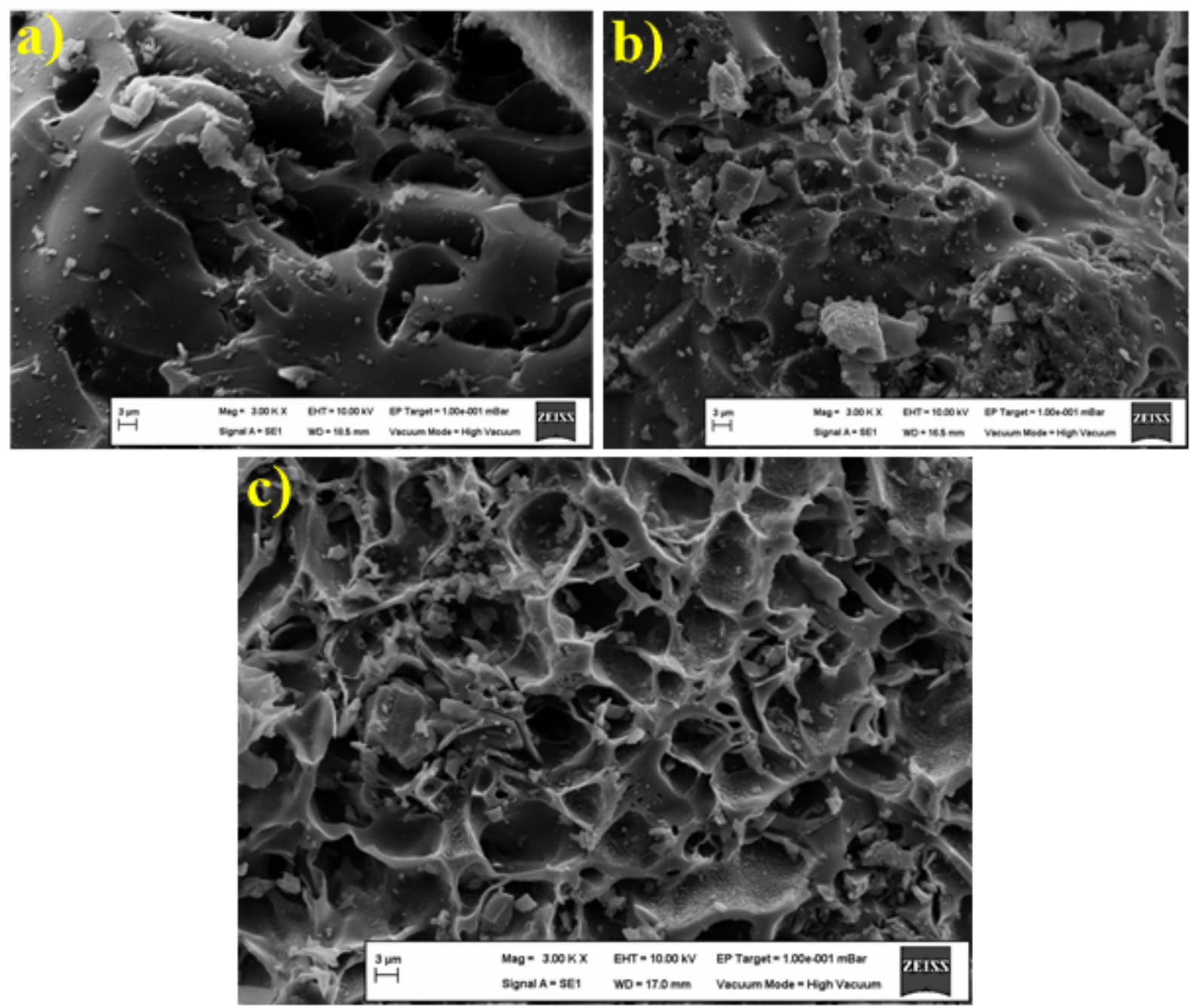
Figure 3

SEM images of AC (a), CdS/AC (b) and Mo-doped CdS/AC (c) materials

Figure 4

XRD patterns of AC, CdS, CdS/AC and Mo-doped CdS/AC materials

Figure 5

EDX spectra of CdS/AC semiconductor material

Figure 6

EDX spectra of Mo-doped CdS/AC semiconductor material

Figure 7

XPS spectra of C 1s (a), Cd 3d (b), S 2p (c) and Mo 3d (d) regions of AC (C 1s peak), CdS/AC (C 1s, Cd 3d and S $2 p$ peaks) and Mo-doped CdS/AC (C 1s, Cd 3d, S 2p and Mo 3d peaks) materials

\section{Supplementary Files}

This is a list of supplementary files associated with this preprint. Click to download.

- GraphicalAbstract.png 